\title{
Ancient basketry on the inside: X-ray computed microtomography for the non-destructive assessment of small archaeological monocotyledonous fragments: examples from Southeast Europe
}

\author{
Mila Andonova* (1)
}

\begin{abstract}
This study proposes non-destructive assessment instrumentation, the X-ray MicroCT scanning, to evaluate archaeological basketry remains prior to any destructive analysis. Three case studies are originating from two archaeological sites in Southeast Europe, with three different stages of preservation (poor, sufficient and very good). In addition, there are two preservation modes - charring and desiccation - along with two conservation situations: treated and untreated with conservation agent fragments. The three different scenarios were chosen to explore the potential range of X-ray MicroCT scanning technology when applied to monocotyledonous small-sized archaeological remains. It was proved that this non-invasive X-ray method is particularly suitable for the often-disadvantaged ancient basketry remains.
\end{abstract}

Keywords: Archaeological basketry, X-ray MicroCT scanning, Non-destructive assessment, X-ray techniques in archaeology

\section{Introduction}

Basketry products are highly informative on social and industrial aspects of past societies because they were highly used for storage, transportation, food collection and preparation, architecture, ritual, and many others. This is why perishable products of material culture were very accurately called "the missing majority" [1], which basketry items are definitely part of. Recently the interest towards archaeological basketry remains has risen along with the number of archaeobotanical studies of such objects [2-5]. Nevertheless, perishable vegetal artefacts, such as plant-based textiles and basketry products, are very rare finds in the archaeology of Southeast Europe.

*Correspondence: mila.andonova@iber.bas.bg; m.andonovae@gmail.com Division of Palaeobotany and Palynology, Institute of Biodiversity and Ecosystem Research, Bulgarian Academy of Sciences, Sofia, Bulgaria
This is mostly due to the specific taphonomic conditions in this part of the world, where archaeobotanical material is generally preserved when charred, rarely when mineralised and very rarely when waterlogged or desiccated. This makes those types of archaeobotanical remains almost invisible in the archaeological record, even if they were an inherent part of the everyday life of past societies [1]. This article explores the application of non-destructive imaging through microCT scanning on particularly sensitive perishable plant remains, such as basketry products.

\section{X-ray microCT scanning in the study of archaeological plant remains \\ Originally designed for medical diagnostics, X-ray com- puted tomography scanning has recently revolutionised several sectors, including palaeontology [6], engineering}


[7], material science $[8,9]$. Precisely the high-resolution modality of X-ray computed tomography (or microtomography, microCT scanning) is the method in the hand of the current research and refers to results visualised at $50-100 \mu \mathrm{m}$ spatial resolution [9]. Since the current study focuses on basketry, and baskets are traditionally made with woody and grass-like plant material, here a brief overview of the existing applications of microCT to archaeological woody and non-woody material will be summarised [10]. The woody plants will also be referred to as dicotyledonous plants, while grass-like plants-as monocotyledons. Both the dicotyledonous (dicots) and the monocotyledonous (monocots) are flowering plants (called angiosperms), but the dicots produce seeds that contain a pair of embryonic leaves (cotyledons) in them, while the seeds of the monocots contain a single cotyledon in the seed embryo.

It should be mentioned that very few previous applications of microCT technology to archaeological monocotyledonous plant parts, excluding seeds or fruits [11], were encountered in the existing scholarship, for example the study of traditional Maōri monocot fibre plants [12]. However, recently, the method was used for the study of heritage wooden objects of all sizes, varying from large Japanese wooden statues [13], Italian or Flemish Medieval musical instruments $[14,15]$ to Renaissance miniature paintings [13]. This non-invasive assessment and analysis tool revealed a great range of "hidden" details of the inner construction and structure of the observed objects, such as applying "invisible" adhesive, micro pins, or micro wooden wedges. Apart from the technical analysis, CT scanning was also applied to the study of wood anatomy of archaeological objects (Table 1). Even if wood anatomical features differ from the anatomy of monocotyledonous plants, the size, shape and overall visual contrast with the surrounding plant tissues is very similar in both plant groups. In addition, the characteristic chemical composition of both wood and grasses is similar, being composed of cellulose, hemicellulose, lignin etc. [16]. These similarities are the argument for reviewing the CT scanning studies on wood samples along with their abundance in contrast to the CT scanning studies on monocots.

However, several obstacles limit the application of the microCT to soft organic tissues, such as archaeological plant material, especially when charred. As low-density materials, plant tissues present low contrast when visualised with X-ray microCT scanning [11, 17], which is determined by the plant material's low absorption of the $\mathrm{X}$-rays [9]. Precisely the low differentiation between the phases of contrast and their boundaries is what causes obstacles in front of the visualisation of natural fibrous materials, such as wood and grasses, and the reason for this is the low atomic number (or the proton number, also Z) of each element, which composes those materials, and which absorbs weakly the X-rays $[17,18]$. The abovedescribed problems have been addressed by applying the phase-contrast technique in combination with X-ray microCT $[17,18]$.

Another challenge proved to be the achieved image resolution, especially visible in the studies on microCT scanning of woody material, where some of the finer anatomical features remained obscured (Table 1). Nevertheless, this is an issue perhaps limited by the availability of microCT instruments, rather than the capability of the scanners, because if the majority of the industrial scanners reach a resolution in the range $5-150 \mu \mathrm{m}$, most nanoCT scanners (also referred to as sub-microCT) are optimised to $0.5 \mu \mathrm{m}$ [7]. On the other hand, almost unavoidably, there was an additional method of analysis to-be-applied to confirm/improve the CT scan for anatomical identification of ancient wood or carpology (seeds and fruits), such as High-Resolution Light Microscopy [11]. Reflected Light Microscopy (RLM) and further $3-\mathrm{D}$ reconstruction of the obtained images (Table 1 ).

\section{Research questions}

Archaeological basketry remains of vegetal origin are a peculiar type of archaeobotanical material characteristic with their extreme perishability, especially in the vast majority of taphonomic scenarios in Southeast Europe. Their unstable condition is mostly due to the pathways of preservation typical for the region-predominantly, they are charred, rarely desiccated and very rarely-waterlogged. This makes the archaeological basketry remains unsuitable for undergoing the necessary manual fragmentation for achieving planes of observation (transversal, tangential and radial in the case of dicotyledonous material) because fragmenting them often means losing them. However, the application of a non-invasive assessment technique could at least partially solve that problem. This was the main rationale that directed this study: could a non-invasive methodology, such as CT scanning, assess the level of preservation of small-sized and brittle archaeological basketry fragments and later aid their botanical identification?

\section{Materials and methods}

This study presents three different archaeological basketry fragments, but all of them were part of objects made with the technique of diagonal twilling (confirmed by the presence of the endings of selvedges of the twilled surface). Diagonal twilling is a plaiting technique, which consists of plaiting several strands, where one set passes over two or more and repeats that in fixed intervals to create an even twilled surface at one plane $[25,26]$. 


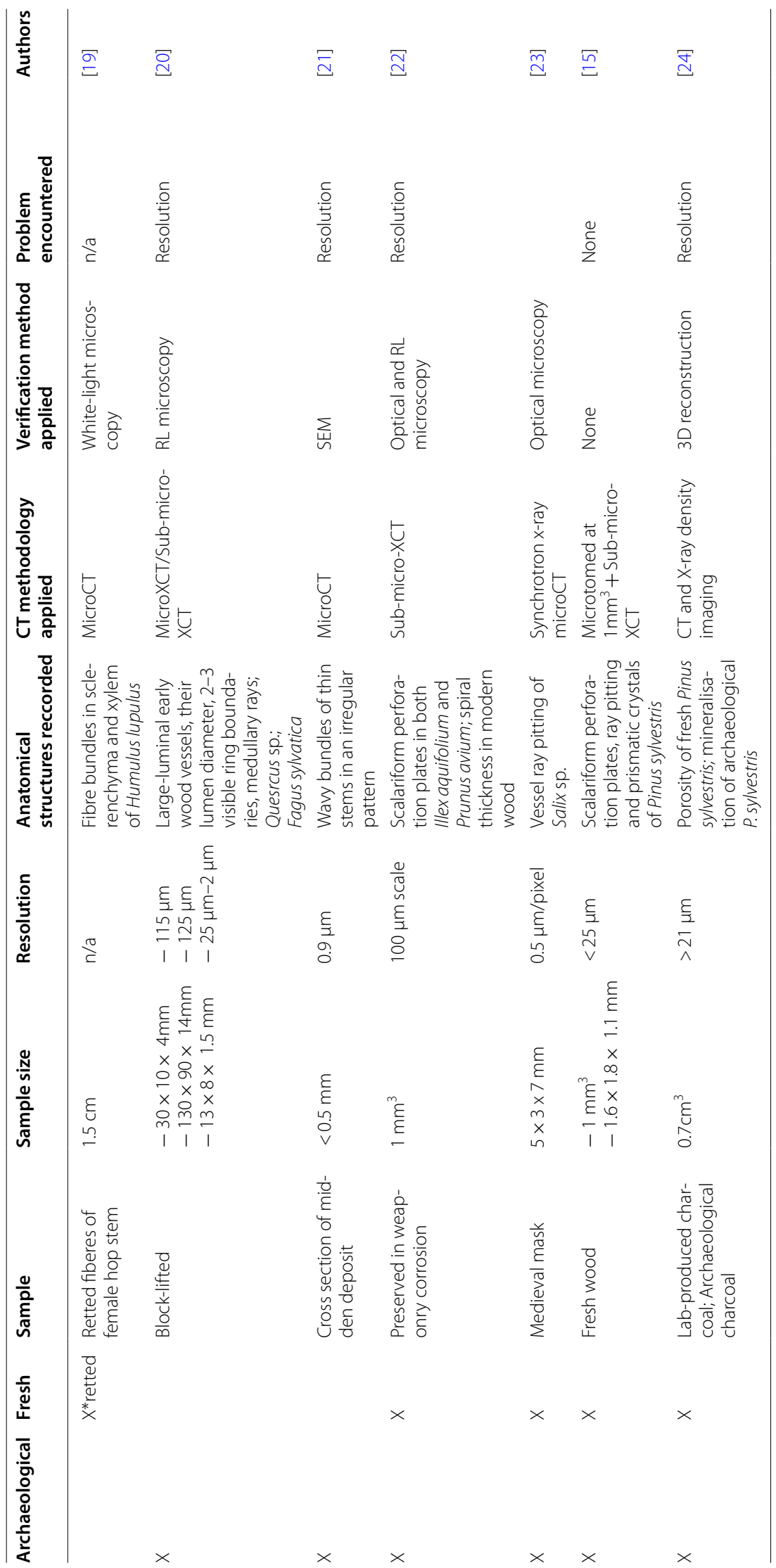


The samples were pre-examined with the application of Reflected Light (RL) and Plain Polarised Light (PPL) optical microscopy (Olympus BX $51^{\circledR}$ equipped with magnification lenses ranging from $10 \times$ to $50 \times$ ) and with the alternation of bright and light field filters (BF-DF). The three basketry fragments are in different stages and modes of preservation. They were selected to represent poor, sufficient and very good preservation of their plant tissues, so the potential of CT-scanning could be tested for different taphonomic environments. The first two fragments, subject to CT-scanning, came from a single object-a twin-handled woven sack (zembil) from the Late Minoan (circa 1450 BC) settlement of Akrotiri (Santorini, Greece), while the third one consists of a woven mat fragment from the Roman burial mound Kitova (1st c. BC-2nd c. AD), located in South-east Bulgaria (Fig. 1).

The sack from Akrotiri (Inventory numbers 035, later 8860,8862 ) is a published item from Pillar Shaft 68A [12]. Its body is made with diagonal twilling technique, while the handles are coiled (coiling is a technique where one strand is being coiled around a bundle of stems/ leaves or around a wooden branch $[25,26]$. The size of the sack is $0.175 \mathrm{~cm}$ in height and $0.275 \mathrm{~cm}$ in diameter [27]. Another smaller basket or pannier (Fig. 2a) was discovered inside vessel 035 together with its content-carbonised barley grains [27, 28]. Object 035 is preserved in a charred mode, and its vegetal tissue is infiltrated with the fine particles of the volcanic tephra, following the Santorini eruption. Besides, at the time of its discovery, the sack and the pannier it contained have been treated with a $10 \%$ solution of thermoplastic resin (Paraloid B-72 ${ }^{\circledR}$ ), to preserve their structure as a whole. The two analysed in this study charred fragments from the sack were sampled from the body weave of the object near the base (Fig. 2a, red arrow).

The mat from Kitova mound is an unpublished item, recovered from the central burial of the mound (Grave 6 ), where a young female individual was covered with a woven mat, perhaps placed as a shroud. The mat was in contact with several large bronze vessels and a wooden box amongst the grave offerings. Based on the inventory, the burial was dated between 1 century $\mathrm{BC}$ and second century $\mathrm{AD}$. The mat is preserved in desiccated mode and as an assemblage of numerous fragments with an approximate surface coverage in situ $0.5 \mathrm{~m} \times 0.7 \mathrm{~m}$. In terms of conservation, the mat was treated with a $10 \%$ solution of the acrylic resin Paraloid B-72 ${ }^{\circledR}$, but prior to its application, a fragment $(2.4 \mathrm{~cm} \times 1.2 \mathrm{~cm})$ was sampled for the purposes of the archaeobotanical analysis (Fig. 2b, red arrow).

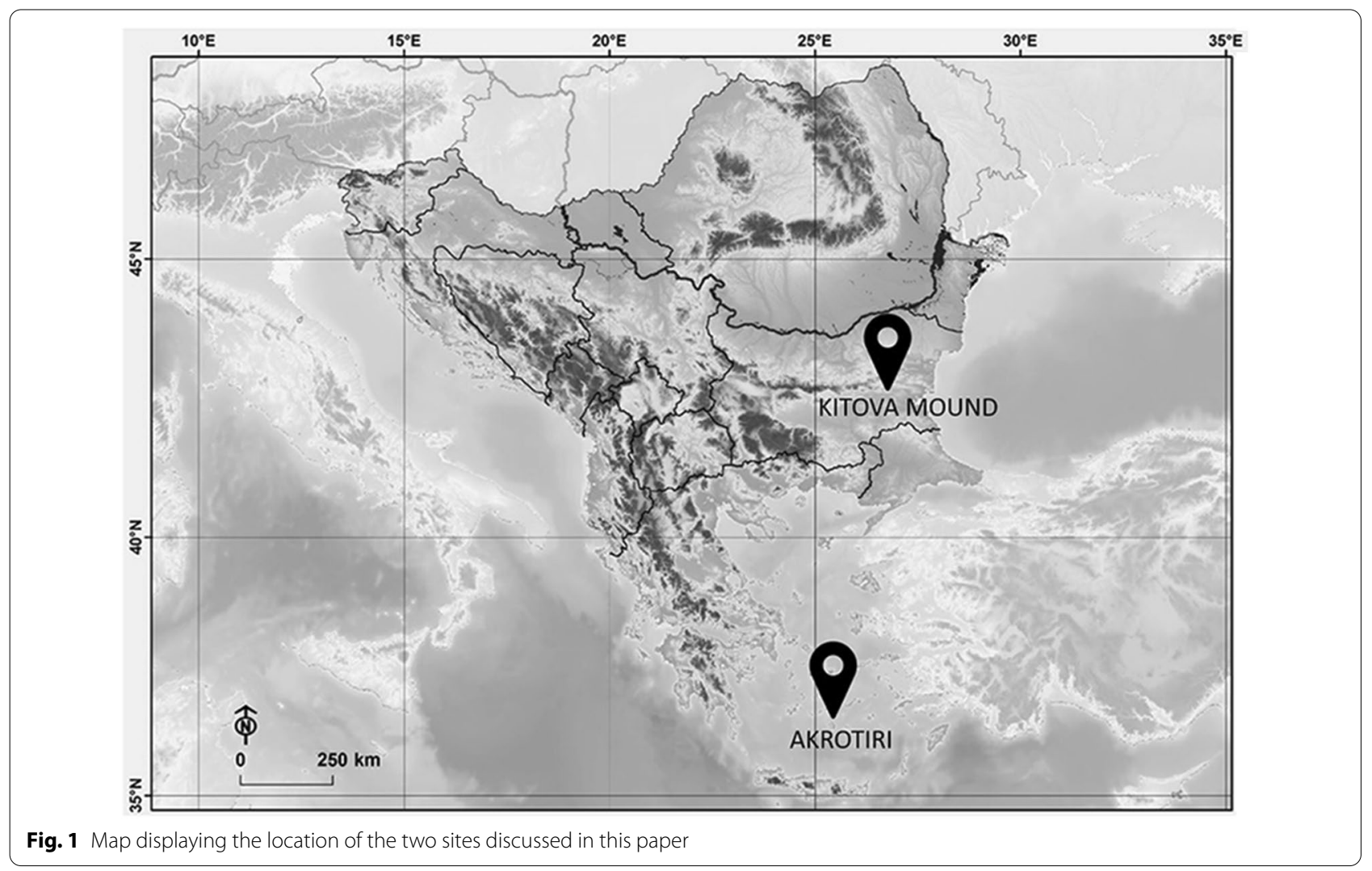



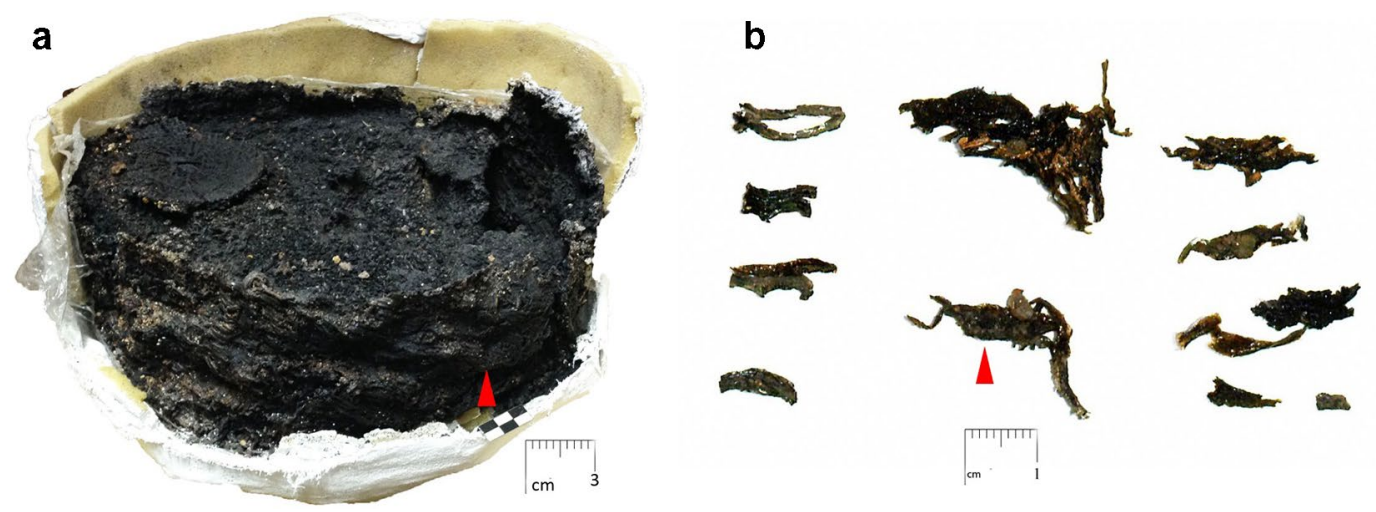

Fig. 2 The two basketry objects, subject to this study, at their stage after the application of a conservation agent: a twilled sack from LM Akrotiri (Object 035, which was subject to SCAN 1 and SCAN 2), b twilled mat from Roman Kitova mound (subject to SCAN 3) and the areas of sampling (red arrows)

The microCT scans were conducted with Phoenix v/ tome $/ \mathrm{x} \mathrm{M}^{\circledR}$ industrial scanner and were performed at the Hounsfield Facility of the University of Nottingham, UK. The scanners' parameters during the scans were: X-ray Tube Energy $=100 \mathrm{kV}$, X-ray Tube current $=75 \mathrm{uA}$, Detector timing $=250 \mathrm{~ms}$, Detector sensitivity $=2$ and Projection images collected $=2891$.The achieved scan resolution came to $8 \mu \mathrm{m}$ due to the relatively large sample sizes (circa $4 \mathrm{~mm}$ in diameter), which determined the FOD (focus-toobject distance) of 818.6(7) $\mu \mathrm{m}$ and 32.74(9) $\mu \mathrm{m}$, operating in magnification $\times 24.9$. The data was collected in FAST scan mode (continuous rotation), while the scan time was $10 \mathrm{~min}$.The scans were analysed with Phoenix datos $/ \times 2.0$ $\mathrm{CT}^{\circledR}$ software, producing three-dimensional images and videos (Additional files 1, 2, 3, 4. The volume was oriented along the $\mathrm{X}$ and $\mathrm{Y}$-axis of the specimen, where the horizontal view $(\mathrm{X})$ consists of a virtual transversal plane (Fig. 3a), while the vertical $(\mathrm{Y})$ shows the virtual longitudinal plane (Fig. 3b). The density of the scanned material is what the radiograph reflects: areas with low X-ray absorption and hence with lower material density are visualised with dark voxels (the volumetric pixel unit used in X-ray CT), while the areas with high $\mathrm{X}$-ray absorption and denser material are visualised with brighter voxels [10, 29, 30]. In addition, the standard radiograph view was combined with "Surface determination mode" (hereafter: SDM) in order to enhance the visibility of the density of the anatomical features of the observed vegetal tissues (as in Figs. 3, 5). The anatomical descriptions of the monocotyledons followed Cuttler (1969), Evert (2006), Metcalfe (1960; 1971) [13,31-33].

\section{Results}

\section{Preparation for CT scanning: light microscopy}

The fragment which is described below as SCAN 1, appeared as an amorphous vegetal mass, consisting
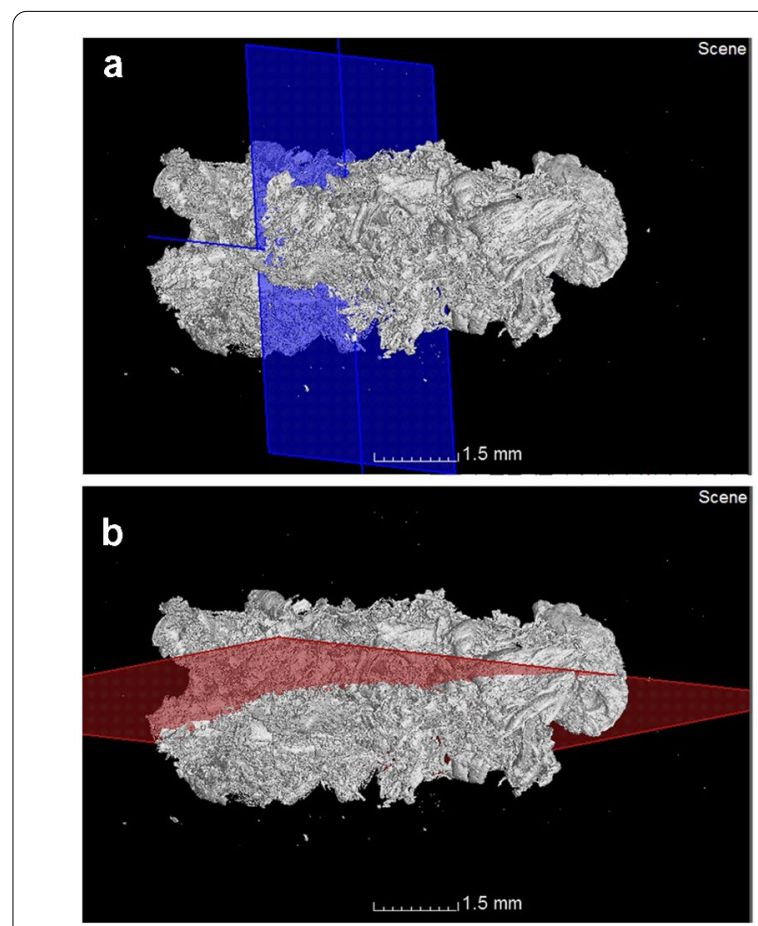

Fig. 3 Snapshot from the Phoenix datos $/ \times 2.0 \mathrm{CT}^{\circledR}$ software: a cutting a virtual transversal plane, $\mathbf{b}$ virtual longitudinal plane

of agglomerated plant tissue. Going deeper into RL microscopy did not reveal any anatomical features, except the parallel venation outline, characteristic of the monocotyledonous plants. However, under less magnification, the stereoscope image displayed several disintegrated plant parts interwoven together as part of the body weave of the studied sack. So, it may be suggested there were leaves and/or stems chosen to create the basketry item. It should be pointed out 
that this fragment was extremely brittle and even during the careful manipulation for optical examination, it was fragmenting further. Here, the main rationale behind the following application of CT scanning was to avoid any manual treatment and still-to assess the level of preservation of the available plant tissues.

Regarding the fragment used in SCAN 2, it became clear that it consisted of two to three stems/leaves of a circular and acute overall outline. When examined under PPL light, the treated with conservation agent surface was polarising the light ejected from the microscope, making any anatomical analysis a difficult task. Only the longitudinal plane, being the epidermal tissue, was observed because obtaining a good transversal section would mean fragmenting (already very) small fragments. Here the dense concentration of stomatal apertures (circa 2 per $50 \mu \mathrm{m}$; Fig. 4b) leads to the assumption that the observed plant part is a leaf. Anatomically wise, some of the stomatal cells' morphology could also be detected: they appeared as non-paracytic and $c f$. superficial with open apertures (Fig. 4b). The better preservation of this fragment (when compared to the previous one) stands out, but yet its small size leads to the application of CT scanning. The last aimed at the evaluation of the preservation stage to take a decision of further manual fragmentation for the purposes of botanical determination. This is of importance, because if fragmentation for botamical analysis was to-be-applied perhaps only a single try would be possible (given the minimal size of the fragment).

Regarding SCAN 3, the preserved plant part consists of a culm or cylindrical leaf with a diameter of circa $2.5 \mathrm{~mm}$ of a monocotyledonous plant, as seen by the parallel arrangements of stomata, distributed along with the preserved epidermal tissue (Fig. 4c). The high density of preserved stomatal cells (circa 3-4/ $1 \mathrm{~mm}^{2}$ ) points in support of both the abaxial epidermis being present (as the adaxial is often absent in cylindrical leaves) and the plant part being determined as a leaf, not a culm. It should be noted that this fragment performed quite well during the manual treatment when adjusted for optical examination. The desiccated stage of preservation ensured a great level of elasticity of the specimen under observation, which was not treated with any conservation agent. However, the transversal view was still quite unclear because of the shrinkage of the anatomical structures due to the deposition process. Here, it was obvious that good preservation of the epidermal tissue was observed, but yet it was uncertain that the ground tissue was still present, which was the question to be answered when CT-scanning was performed.

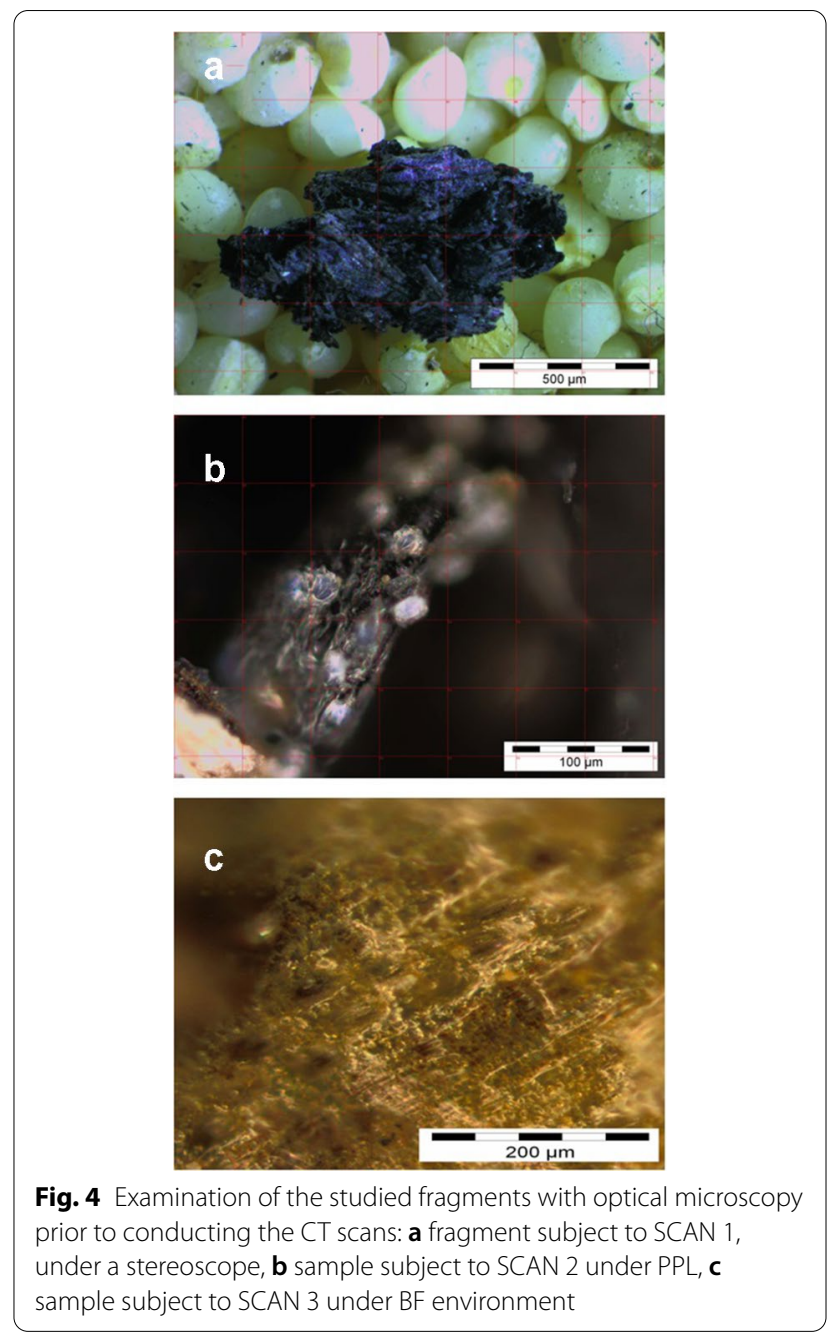

\section{MicroCT scanning results \\ SCAN 1 (poor preservation of fragment from object 035 of LM Akrotiri)}

The first fragment that underwent the microCT scanning was evaluated as not very promising when examined with optical microscopy. This was the reason for testing a microCT scanning of a small section of this fragment (circa $4 \times 6 \mathrm{~mm}$ ). Since the grey-tone images (or volume images) were not sufficiently informative, here an SDM was applied, so the structures appear enhanced (see the visual 3-D model at Additional files 1, 2, 3, 4, but we lost the density determination available in the volume view. At the overview image (Fig. 5a), it was possible to see the twilling elements, even in a quite distorted stage. However, separate cylindrical plant parts (stems and/or leaves) appeared pronounced (Fig. 5b), perhaps following the general plaiting direction of the item (Fig. $5 \mathrm{c}$, red arrows). In addition, undulated structures of the epidermal tissue of these cylindrical vegetative parts were also 


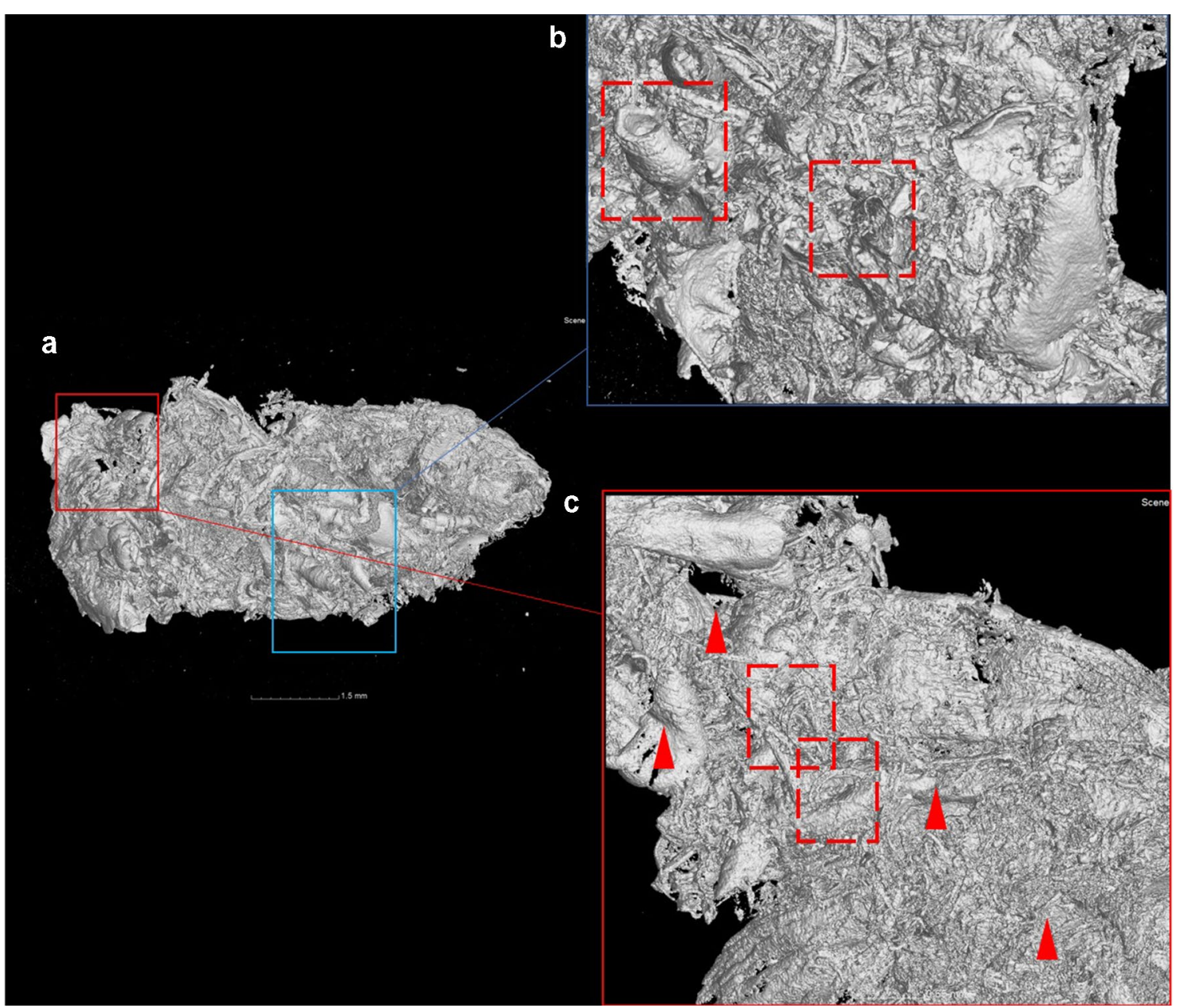

Fig. 5 SCAN 1: a an overview, b details on tilted transversal view, c details on tangential view

recorded, and it is assumed they represent the long epidermal cells of the observed monocotyledonous specimen (Fig. 5b, marked). When an animated 3-D model was created, it became clear that multiple epidermal tissues were "spiking" from this deformed fragment. Nevertheless, their overall structure was also detectable: the majority of the recorded plant parts are cylindrical, and this is a result that would definitely aid the botanical determination of this fragment (Additional files 1, 2, 3, 4). It should be noted that the animation also illustrated the voids between the separate plant parts very well: firstly because of the poor preservation mode and secondlydue to the twilling technique, which shaped this basketry object.

\section{SCAN 2 (sufficient preservation of fragment from object 035 of LM Akrotiri)}

A fresh cut was produced in order to obtain a surface suitable for observation (circa $1.5 \times 2 \mathrm{~mm}$ ). The sharp light voxels, which outline the cut of the observed fragment, are an artefact created by force applied when performing the cut, hence-compressing the anatomical structure. Nevertheless, the achieved model provides good visibility of darker and lighter voxels, even if the scanned carbonised fragment does not display excellent density. The overview of the fragment showed the presence of the epidermal tissue (Fig. 6a) and its compact cover with tephra particles and the conservation agent layer (the granular appearances on Fig. 6c). The transversal view illustrated the plant part(s) under observation was deformed-this is particularly visible in the compressed aerenchymatic cavities outlining the cross-section on the outer part (Fig. 6b). Moving towards the inside, it was detected that the mesophyll is partially preserved and that there are indications for the presence of vascular bundles (Fig. 6b, marked). However, the transversal view also shows that the sampled fragment consists of at least two plant parts because the second layer of aerenchymatic cavities is 


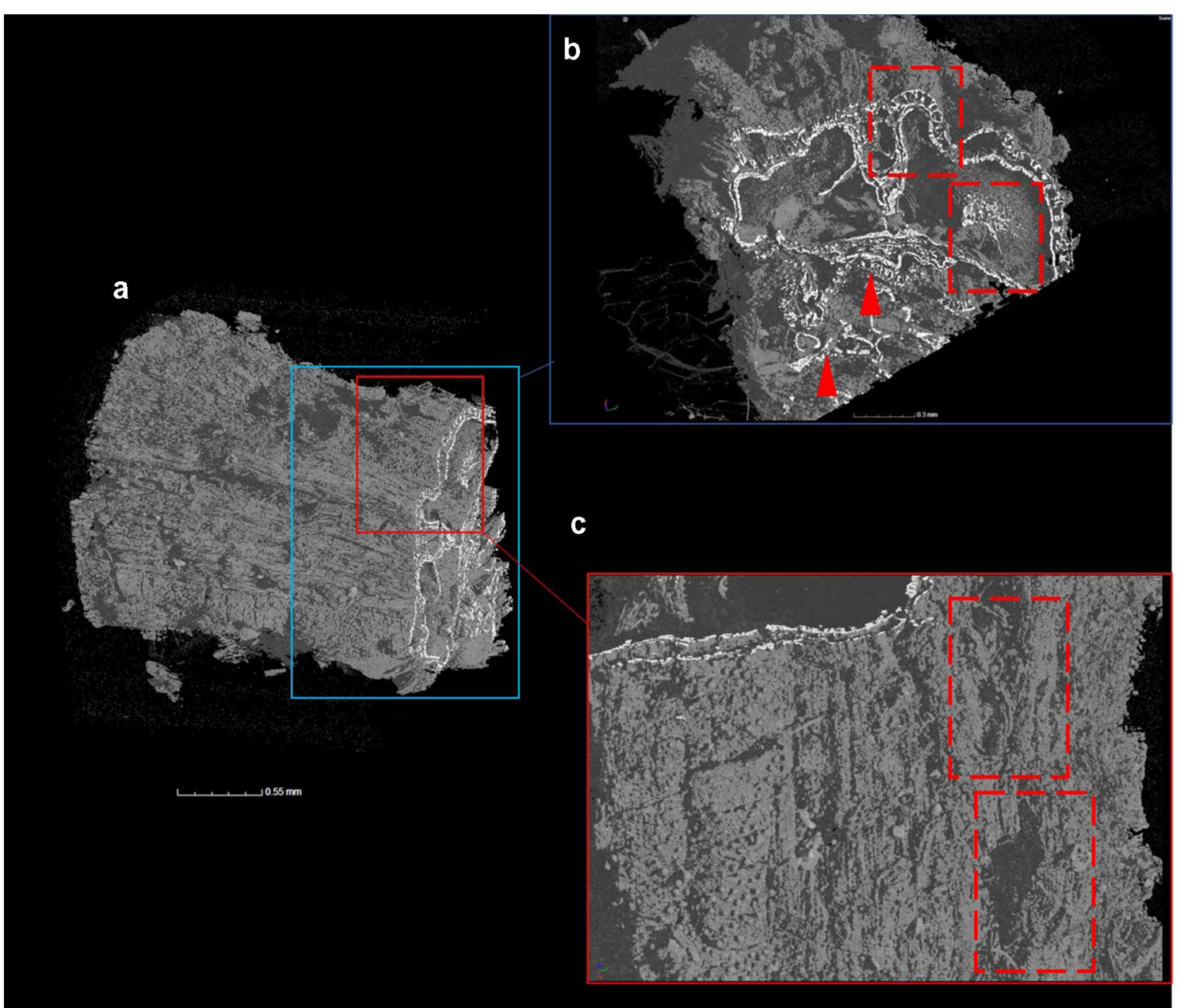

Fig. 6 SCAN 2: a overview, b transversal view, c epidermal view

detected, being attached to the first plant part; in addition, at the very bottom of the image, there may be a third plant part too (Fig. 6b, red arrows). This may be the case when twilling the actual basket-a bundle of plant parts (i.e. three stems) may have been applied in each strand of the plaits, for adding additional strength. The epidermal view (Fig. 6c) does not reveal the anatomical features of the tissue in great detail, but it should be pointed out that the outline of the stomatal apertures is detected, and even more-their appearance as sunken stomata could be suggested (Fig. 6c, marked).

\section{SCAN 3 (good preservation of a mat fragment from the Roman Kitova mound)}

The uncharred desiccated fragment from the Roman burial mat was reduced to circa $6 \times 3 \mathrm{~mm}$ in size and it did provide a very clear X-ray view with the light voxels illustrating the dense preserved vegetal tissues and (excluding the super-light voxels-artefacts from the cut, during the sample preparation), darker ones showing the less compact tissue and the black-displaying the air voids. The overview of the fragment (Fig. 7a) proved that the porous tissues are almost completely decomposed, which is particularly visible at the transversal section (Fig. 7b). The organs contained in the ground tissue, as the vascular bundles, together with the highly porous aerenchymatic and parenchymatic tissues, seem to have decomposed (Fig. 7b, c). On the other hand, the epidermal tissue, shown on the virtual longitudinal plain, is preserved in much better condition, making it even possible to identify the individual leaves forming the weave of the fragment (Fig. 7b, c, marked). It seems that the specimen had preserved its cuticular layer because of its stage of desiccation (and not charring), which appears as smooth ridges by the parallel venation. In addition, the $\mathrm{X}$-axis shows elongated structures with identical tissue density, as the already identified epidermis: these are fibres of the sclerified sheaths surrounding the vascular bundles 


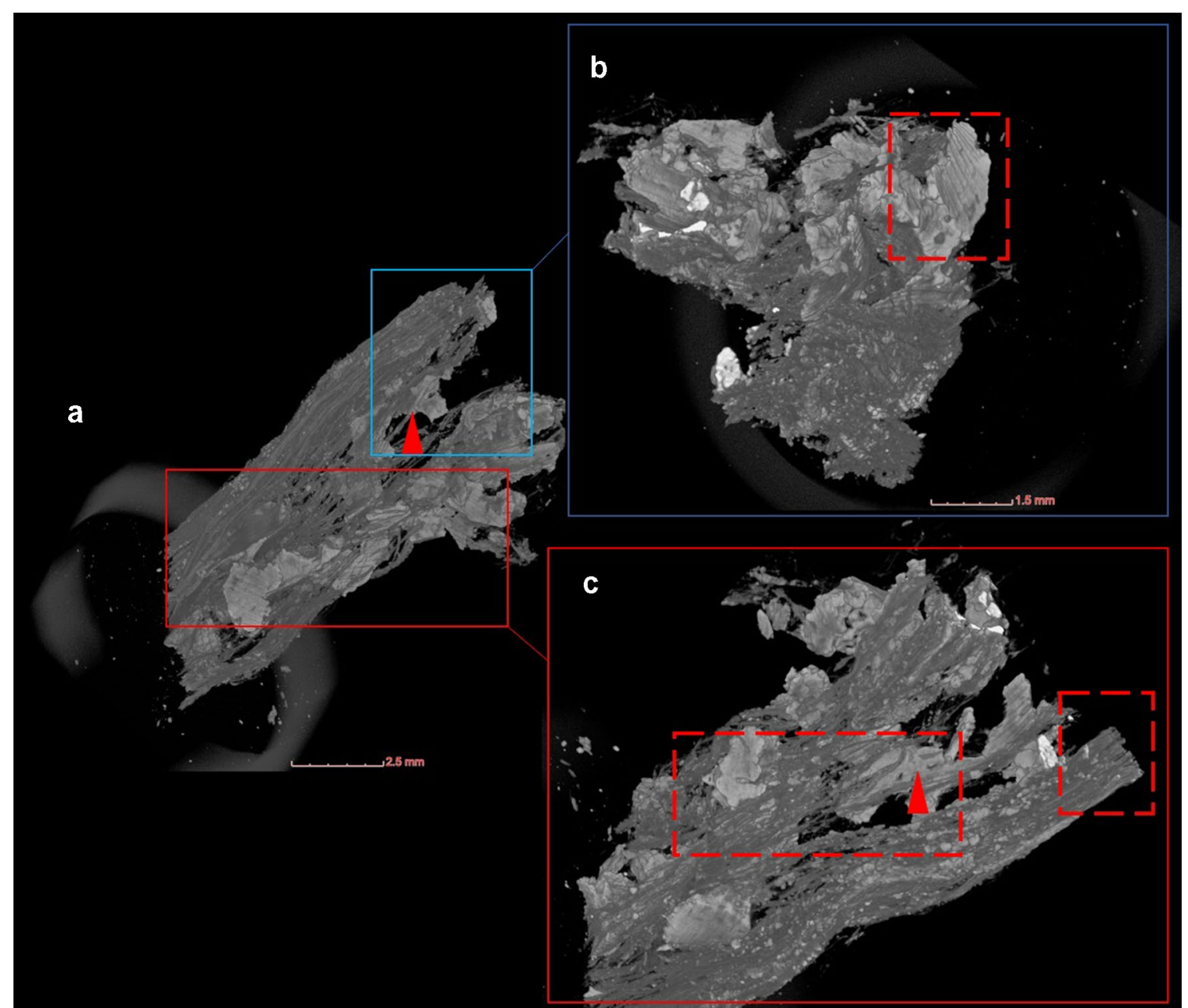

Fig. 7 SCAN 3: a overview, b transversal view, c tilted longitudinal view

(which remained from the phloem in the vascular bundles, Fig. 7a, c, red arrows).

\section{Discussion}

\section{Is it worth breaking? Non-destructive assessment prior}

\section{to destructive analysis}

$\mathrm{X}$-ray microCT scanning technology allows a nondestructive way to evaluate the plant tissues' stage of preservation, the tissues' location (articulated or disarticulated of their anatomical sequence) and a partial overview of the organs they contain, their shape, size and order. This non-invasive assessment proves to play a critical role when proceeding to further destructive analysis. By applying a microCT scan, one can evaluate the readiness and suitability of a certain archaeobotanical fragment for further manual fragmentation for botanical identification. For example, if the microCT scan concludes that there is no tissue preserved under the epidermis, for the case of monocots, no further fragmentation would be needed, but only analytical observation of the epidermal tissue. On the contrary, if the microCT scan confirms the ground tissue preservation, further fragmentation could be attempted again in the case of monocots.

However, there are scenarios where manual fragmentation would not be applicable, even if sufficient preservation status is confirmed by CT scan. These could be the cases where the sample size is extremely small and/or the sample itself is very brittle. This is very likely the case with carbonised basketry remains and precisely monocotyledonous remains. Numerous factors make charred monocotyledonous stems and leaves much more unstable than wood charcoal, including their different mechanical properties, the chemical composition of tissues etc. [10]. However, conducting a non-invasive observation, such as CT scanning, could obtain the maximum information if we are about to lose the fragment under-examination when breaking it for obtaining planes of observation. 
In addition, given the rarity of archaeological basketry remains in Southeast Europe, often these objects are difficult to sample for the purposes of archaebotanical analysis. One reason behind this is that sampling involves physical breakage of the preserved objects' surface. And even more-if we would like to obtain a good dataset on the chosen raw plant material, we should sample from multiple areas of the basketry item. This brings forward another issue-the disturbance of the archaeological object as a whole for exhibiting purposes. Perhaps this is the scenario when the financial cost of CT scanning should be brought into discussion: yes, this type of analysis is relatively expensive, but not more than conducting Scanning Electron Microscopy, for example (if we take into account a single session per each method). Nevertheless, microCT scanning could be applied to extremely small vegetal fragments, below the accepted sample size for standard charcoal study [34], which would require an almost invisible breakage from the archaeological object. In addition, the sample preparation for CT does not include any treatment of the surface (as the coating is necessary for SEM), which renders the method minimising the invasive analytical procedures necessary for archaeobotanical investigation. Hence, if we are aiming at obtaining an evaluation and assessment information with minimal physical harm to the original perishable archaeological object (thus sampling a fragment of minimal size) and at the application of a non-invasive technique (so we preserve the fragments to later apply an invasive method, if this is necessary), the cost of conducting CT scanning seems rational and judicious.

Too small, too brittle: challenging the minimal sample size The sample size and the level of preservation do not ultimately pair together-for example, not always a small sample size means insufficient preservation, and vice versa, the optimal preservation does not promise a sufficient sample size. In other words, we may analyse a very well preserved but extremely small sample, which is often the case with archaeological basketry remains in the study region; or we may also retrieve a large sample of poor insufficient preservation, which would not be suited for archaeobotanical analysis. Here the term "sufficient" is used for the stage of preservation that ensures manual fragmentation for conducting analysis for botanical determination of charred monocotyledonous fragments.

Whichever the case, this is where the assessment with the application of microCT scanning proves useful and informative-the interim stage between the initial examination and the destructive analysis for identifying the plant species. However, the case of a well-preserved small sample is particularly sensitive mainly because of the analytical approach to be chosen. If we are handling a sample with good potential for botanical determination (for example, pre-evaluated with optical microscopy) but below the accepted sample size for botanical determination, then the destructiveness of the analytical method is of major importance. Here is also where the general idea of what is a minimal sample size could be questioned. If the recommended minimal fragments' size is $2 \mathrm{~mm}^{3}$ [34] for wood charcoal, then for grassy plant remains, it could possibly be lowered because the diagnostic anatomical structures for monocots are smaller in size. A good example is the registered circa 3-4 stomatal apertures per $1 \mathrm{~mm}^{2}$ at the fragment subject to SCAN 3 (Fig. 4b). This means that there should be long and/or short cells in the interim areas too, which all contribute to the features at a cellular level, necessary for obtaining a botanical identification.

Hence the potential for evaluation, but also the botanical determination of monocotyledonous plant material retrieved from archaeological excavations, with the application of X-ray CT technologies (as microCT and nanoCT scanning) should be highlighted as high and promising. However, access to sub-micron CT scanners (nanoCT) is costly and difficult, in contrast to industrial CT scanners, for example, which have become more and more popular and widely used in material science (see "X-ray microCT scanning in the study of archaeological plant remains"). Therefore, the accessibility to the analytical instrumentation is one of the practicalities of CT scanning technology, which should be considered when designing such a study. Nevertheless, archaeological basketry remains' scarcity, fragility, and informative potential may be worth choosing this method, which allows virtual sectioning and avoids the sample preparation and treatment associated with microscopy methods $[11,18]$.

\section{Testing of different preservation types}

The first fragment, which underwent CT scanning (SCAN 1) was charred and in a particularly poor state of preservation: its whole surface was impregnated with volcanic tephra particles, and its outer tissues were sealed with a conservation agent. However, even at this level of preservation, the conducted CT scanning yet revealed details, preventing the fragmentation of this very unstable sample. The second sample analysed in this paper (SCAN 2) was in quite stable preservation modecharred and not heavily impacted by volcanic particles. Even if this sample's optical examination was informative, the CT scan still allowed for the recording of further details, such as the status of plant tissues. The last fragment (SCAN 3) was desiccated and presented great elasticity when analysed, along with very well-preserved plant anatomy. Yet, in this best-case scenario, the CT scan showed the deformation of the inner vegetal tissues, 
even if the outer ones had a good preservation state. The three case studies showcase the potential of the method and its applicability to wider taphonomic environments. Even if the botanical determination approach could differ depending on whether the sample is charred, desiccated, mineralised or waterlogged, the CT scanning assessment would be valid for all described contexts.

\section{Conclusion}

There are several advantages and disadvantages in the application of X-ray microCT scanning to study archaeological basketry remains. Amongst the pros are that CT scanning is a generally non-invasive technique with the ability to visualise an external and/or internal structure in a non-destructive way. It eliminates the interference with the object, while conventional microscopy requires destructive methods, such as sectioning and achieving planes of observation. These are time-consuming and potentially harm the object, which renders microscopy as a technique unsuitable for the majority of the products of perishable material culture. CT scanning also represents the object's original structure and features, creating a three-dimensional image [15].

The above advantages of the CT technology are fully valid for the three case studies discussed in this article. Since the studied archaeological basketry remains were of small size and various stability and status of preservation, their further examination with microscopy methods would be risky and could potentially destroy them. However, the application of microCT allowed the detection of preserved plant tissues, such as the epidermis, along with the absence of those-such as the partially preserved mesophyll. In addition, both small and large features were visualised-from the overall weaving pattern (twilling technique), to the single cylindrical plant parts, such as stems of monocotyledonous plants could be. Another aspect where microCT scanning proved successful was at the examination of poorly preserved small-sized fragments, where their technical and anatomical features (basketry technique and preserved plant parts) were almost non-detectable with microscopy methods.

On the contrary, one of the major barriers to be overcome to render the CT technology from assessment and evaluation method to method for botanical identification and analysis of archaeological monocotyledonous basketry remains the available resolution potential, or in other words, the accessibility of CT instrumentation. This means that if sub-micron CT technology (nano CT) becomes more widely available for research purposes in archaeology and particularly archaeobotany, this will allow for detailed anatomical observation and conclusive botanical analysis.
Abbreviations

AD: After death; BF: Bright field; BC: Before Christ; CT: Computed tomography; DF: Dark field; FOD: Focus to object distance; RLM: Reflected light microscopy; SDM: Surface determination mode.

\section{Supplementary Information}

The online version contains supplementary material available at https://doi. org/10.1186/s40494-021-00631-z.

Additional file 1. Animated model produced during SCAN 1 in the $X$-axis: Twilled sack from LM Akrotiri (Object 035).

Additional file 2. Animated model produced during SCAN 1 in the Y-axis: Twilled sack from LM Akrotiri (Object 035).

Additional file 3. SCAN 3 in the X-axis: Twilled mat from Roman Kitova mound.

Additional file 4. SCAN 3 in the Y-axis: Twilled mat from Roman Kitova mound.

\section{Acknowledgements}

This research was funded by the Vice-Chancellor Scholarship for Research Excellence of the University of Nottingham, UK (RFDX42DB1). I am very thankful to Dr Craig Sturrock from the Hounsfield Facility at the University of Nottingham, the UK, for the assistance when preparing and conducting the CT scans. Acknowledgements are also brought to the site directors, who kindly provided the permission to study the basketry remains presented in this paper: Prof. Christos Doumas, directing the field campaigns at Akrotiri, Thera and Ms Diana Dimitrova, who directed the campaign at Kitova mound. This study would not have been possible without the valuable work of the conservators employed in the conservation of the basketry objects: Mr Manolis Chamaoui and Prof. Georgi Mavrov. In addition, I am also thankful to Dr Anaya Sarpaki, Dr Sophia Vakirtzi, Ms Anelia Nikolova for their assistance when obtaining the samples subject to this study. I also acknowledge Dr Alexandra Livarda and Dr Dimiter Katsarski for reading earlier versions of this paper and providing valuable advice. Last, but not least aknowledgments are brought to the two anonymous reviewers, who contributed to the improvement of this paper with their constructive suggestions.

\section{Authors' contributions}

MA, exclusively. The author read and approved the final manuscript.

\section{Funding}

This research was funded by the Vice-Chancellor Scholarship for Research Excellence of the University of Nottingham, UK (RFDX42DB1).

Availability of data and materials

Data will be uploaded as additional files to this paper or in a data repository (Mendeley Data or other).

\section{Declarations}

Competing interests

The authors declare that they do not have any competing interest.

Received: 9 July 2021 Accepted: 18 November 2021

Published online: 10 December 2021

\section{References}

1. Hurcombe L. Perishable material culture in prehistory: investigating the missing majority. Oxford \& New York: Routledge; 2014.

2. Herrero-Otal M, Romero-Brugués $S$, Piqué HR. Plants used in basketry production during the Early Neolithic in the north-eastern Iberian Peninsula. Veg Hist Archaeobot. 2021;30:729-42. https://doi.org/10.1007/ s00334-021-00826-1. 
3. Di Lernia S, N'siala I, Mercuri A. Saharan prehistoric basketry. Archaeological and archaeobotanical analysis of the early-middle Holocene assemblage from Takarkori (Acacus Mts, SW Libya). J Archaeol Sci. 2012;39:1837-53. https://doi.org/10.1016/j.jas.2012.01.026.

4. Brinkkemper $\mathrm{O}$, Joosten I. The identification of plant fibres from the shipwreck Aanloop Molengat. Interne Rapportage project Aanloop Molengat. 2012. https://www.researchgate.net/publication/303524017_The_ident ification_of_plant_fibres_from_shipwreck_Aanloop_Molengat. Accessed 6 Oct 2021.

5. Borojevic T, Mountain R. Microscopic identification and sourcing of ancient Egyptian plant fibers using longitudinal thin sectioning. Archaeometry. 2014;55:81-112. https://doi.org/10.1111/j.1475-4754.2012. 00673.x.

6. Cunningham J, Rahman I, Lautenschlager S, Rayfield E, Donoghue Ph. A virtual world of paleontology. Trends Ecol Evol. 2014;29:347-57. https:// doi.org/10.1016/j.tree.2014.04.004

7. Plessis A, Broeckhoven Ch, Guelpa A, Gerhard de Roux S. Laboratory X-ray micro-computed tomography: a user guideline for biological samples. GigaScience. 2017;6:1-11. https://doi.org/10.1093/gigascience/gix027.

8. Tuniz C, Zanini F. Microcomputerized tomography (MicroCT) in archaeology. In: Smith C, editor. Encyclopedia of global archaeology. Cham: Springer; 2018. https://doi.org/10.1007/978-3-319-51726-1_675-2.

9. Stock S. Microcomputed tomography. Methodology and applications. London: CRS Press, Taylor and Francis group; 2009.

10. Beailieu J, Dutilleul P. Applications of computed tomography (CT) scanning technology in forest research: a timely update and review. Can J For Res. 2019:49(6):1173-88. https://doi.org/10.1139/cjfr-2018-0537.

11. Calo C, Rizzuto M, Carmello-Guerreiro S, Dias C, Wattling J, Schock M, Zimpel C, Furquim L, Pugliese F, Neves E. A correlation analysis of light microscopy and X-ray MicroCT imaging methods applied to archaeological plant remains' morphological attributes visualization. Sci Rep. 2020;10(1):15105. https://doi.org/10.1038/s41598-020-71726-z.

12. Smith C, Blair K, Lowe B. Identification of historical plant material using micro-computed tomography. Stud Conserv. 2013;58:256-68. https://doi. org/10.1179/2047058412Y.0000000043.

13. Morigi M, Casali F, Bettuzzi M, Bianconi D, Brancaccio R, Cornacchia S, Pasini A, Rossi A, Aldrovandi A, Cauzzi D. CT investigation of two paintings on wood tables by gentile da Fabriano. Nucl Instrum Meth Phys. 2007;580:735-8. https://doi.org/10.1016/j.nima.2007.05.140.

14. Sodini N, Dreossi D, Chen R, Fioravanti M, Giordano A, Herrestal P, Rigon L, Zanini F. Non-invasive microstructural analysis of bowed stringed instruments with synchronisation radiation X-ray micro-tomography. J Cult Herit. 2012;13(3):44-9. https://doi.org/10.1016/j.culher.2012.04.008.

15. Bulcke J, Boone M, Acker J, Stevens M, Hoorebeke L. X-ray tomography as a tool for detailed anatomical analysis. Ann For Sci. 2009;55(5):66-508. https://doi.org/10.1051/forest/2009033.

16. Gale R, Cuttler D. Plants in archaeology. Identification manual of vegetative plant materials used in Europe and the southern Mediterranean to C. 1500. London: Westbury AND Royal Botanic gardens, Kew; 2000.

17. Mayo S, Stevenson A, Wilkins S. Microcomputerized tomography (MicroCT) in archaeology. Materials. 2012. https://doi.org/10.3390/ma50x 000x

18. Mancini L, Tromba G, Zanini F. Structural microanalysis with synchrotron radiation: archaeometric applications at Elettra. J Neutron Res. 2006;14(1):75-9. https://doi.org/10.1080/10238160600673300.

19. Lukesova H, Andersen H, Kolinova M, Holst B. Is it hop? Identyfying hop fibres in a European historica context. Archaeometry. 2019;61:494-505. https://doi.org/10.1111/arcm.12437.

20. Stelzner J, Million S. X-ray computed tomography for the anatomical and dendrochronological analysis of archaeological wood. J Archaeol Sci. 2015;55:188-96. https://doi.org/10.1016/j.jas.2014.12.015

21. Huisman J, Ngan-Tillard D, Tensen M, Laarman J, Raemaekers D. A question of scales: studying Neolithic subsistence using micro CT scanning of midden deposits. J Archaeol Sci. 2014;49:585-94. https://doi.org/10. 1016/j.jas.2014.05.006

22. Haneca C, Deforce K, Boone M. X-ray sub-micron tomography as a tool for the study of archaeological wood preserved through the corrosion of metal objects. Archaeometry. 2012;54:893-905. https://doi.org/10.1111/j. 1475-4754.2011.00640.x.
23. Mizuno S, Torizu R, Sugiyama J. Wood identification of wooden mask using synchroton X-ray microtoography. J Archaeol Sci. 2010;37(11):2842-5. https://doi.org/10.1016/j.jas.2010.06.022.

24. Bird M, Ascough P, Ascough L, Young I, Wood C, Scott A. X-ray microtomographic imaging of charcoal. J Archaeol Sci. 2008;35:2698-706. https://doi.org/10.1016/j.jas.2008.04.018.

25. Adovasio J. Basketry technology. A guide to identification and analysis. Chicago: Aldine Manuals on Archaeology; 1977.

26. Wendrich W. The world according to basketry. An ethno-archaeological Interpretation of Basketry Production in Egypt. Leiden: Centre for Nonwestern Studies; 2012. Permalink: https://escholarship.org/uc/item/ 6n42w0rg

27. Beloyanni M. Basketry: a diachronic art and its products at Prehistoric Akrotiri. A $\wedge \Sigma$. 2007;5:46-88

28. Sarpaki A. A palaeoethnobotanical study of the West House, Akrotiri, Thera. Ann Br School Athens. 1992;87:219-30.

29. Kozatsas J, Kotsakis K, Sagris D, David K. Inside out: assessing pottery forming techniques with micro-CT scanning. An example from Middle Neolithic Thessaly. J Archaeol Sci. 2018;100:102-19. https://doi.org/10. 1016/j.jas.2018.10.007.

30. Mansbridge, Ch. CT scan interpretation. 2015. http://www.oscestop.com/ CT\%20interpretation.pdf. Accessed 6 Oct 2021.

31. Cuttler D. Anatomy of the monocotyledons. IV. Juncales. Oxford: Clarendon Press; 1969.

32. Evert R. Esau's plant anatomy. Meristems, cells and tissues of the plant body - their structure, function and development. New Jersey: Wiley; 2006.

33. Metcalfe CR. Anatomy of the monocotyledons. I. Graminae. Oxford: The Clarendon Press; 1960.

34. Asouti E, Austin Ph. Reconstructing woodland vegetation and its exploitation by past societies, based on the analysis and interpretation of archaeological wood charcoal macro-remains. Environ Archaeol. 2005;10:1-18. https://doi.org/10.1179/env.2005.10.1.1.

\section{Publisher's Note}

Springer Nature remains neutral with regard to jurisdictional claims in published maps and institutional affiliations.

\section{Submit your manuscript to a SpringerOpen ${ }^{\circ}$ journal and benefit from:}

- Convenient online submission

- Rigorous peer review

- Open access: articles freely available online

- High visibility within the field

Retaining the copyright to your article

Submit your next manuscript at springeropen.com 